\title{
Antioxidative activity and total phenolic compounds of leaf, root and petiole of four accessions of Centella asiatica (L.) Urban
}

\begin{abstract}
Antioxidative activity and total phenolic compounds of root, leaf and petiole of four accessions of Centella asiatica (L.) Urban, namely CA 01, CA 05, CA 08 and CA 11, were evaluated. Antioxidative activity of the extracts was measured using the ferric thiocyanate (FTC) method and thiobarbituric acid (TBA) test. The antioxidative activities were then compared with that of Ü-tocopherol (natural antioxidant) and butylated hydroxytoulene or BHT (synthetic antioxidant). The results showed that CA 01 and CA 05 had the highest antioxidative activities among the accessions tested. Results also showed that both leaf and root of C. asiatica had high antioxidative activity, which was as good as that of Ŭ-tocopherol. The total phenolic content, determined according to the Folinï Ciocalteu method, varied from 3.23 to $11.7 \mathrm{~g} / 100 \mathrm{~g}$ dry sample, and showed strong association $(\mathrm{r} 2=0.90)$ with antioxidative activity. The results suggest that phenolic compounds are the major contributors to the antioxidative activities of $\mathrm{C}$. asiatica.
\end{abstract}

Keyword: Centella asiatica; Antioxidative activity; Ferric thiocyanate; Total phenolic content 